\title{
A concepção do ensino médio integrado e o ensino crítico de línguas estrangeiras: convergências e aproximações
}

\author{
Fernando Zolin-Vesz \\ IFMT \\ Veralúcia Guimarães de Souza \\ IFMT
}

\begin{abstract}
Resumo
Este texto propõe uma discussão sobre o papel das línguas estrangeiras no contexto do ensino médio integrado. A partir da busca pela superação da dualidade entre ensino propedêutico e ensino técnico, que se constitui em um dos pressupostos do ensino médio integrado, apresentamos uma proposta crítica e interdisciplinar de trabalho com a língua inglesa para um curso de agropecuária. A discussão aponta para a contribuição do ensino crítico de línguas estrangeiras na formação de um aluno engajado sócio-politicamente no mundo do trabalho a fim de que possa compreendê-lo e que busque outras realidades possíveis.
\end{abstract}

Palavras-chave: ensino de línguas estrangeiras, ensino médio integrado, criticidade, interdisciplinaridade.

\begin{abstract}
The purpose of this paper is a discussion of the role of foreign languages in the integrated high school. In order to overcome the duality between a general culture in contrast to a technician culture, which is one of the objectives of the integrated high school, this paper presents a critical and interdisciplinary educational proposal for English classes in a farming and cattle-raising course. The discussion points out the contribution of critical foreign language teaching which promotes the students' social and political engagement in the world of work, in order to understand it and seek other possible realities.
\end{abstract}

Key Words: foreign language teaching, integrated high school, criticism, interdisciplinarity.

\section{INTRODUÇÃO}

O ensino médio integrado é aquele possível e necessário em uma realidade conjunturalmente desfavorável - em que os filhos dos trabalhadores precisam obter uma profissão ainda no ensino médio, não podendo adiar este projeto para o nível superior de ensino - mas que potencialize mudanças para, superando-se essa conjuntura, constituir-se em uma educação que contenha elementos de uma sociedade justa. (Frigotto et al, 2005) 
O Decreto $\mathrm{n}^{0}$ 5.154, de 23 de julho de 2004, estabelece as diretrizes e bases da educação profissional e, segundo Frigotto et al (2005), propõe a possibilidade de uma formação geral integrada à educação profissional em contraposição ao dualismo da educação brasileira vigente até o momento. Este dualismo expressava-se, de acordo com Frigotto et al (op. cit.), no "falso dilema” sobre a finalidade da educação brasileira: “destina-se à formação propedêutica ou à preparação para o trabalho?” (Frigotto et al, 2005, p. 31).

A partir do referido decreto e do Documento Base da Educação Profissional Técnica de Nível Médio Integrada (2007), o ensino médio assume, portanto, a concepção integrada entre a formação geral dos alunos e a sua formação profissional. Com esta integração, possibilita-se ao aluno estudar os problemas de uma área profissional em suas múltiplas dimensões, tais como econômica, social, política, cultural e técnica. Isto implica, desta forma, conceber a interdisciplinaridade como necessidade e como princípio organizador do currículo, pois, de acordo com o Documento Base, “os conceitos de diversas disciplinas seriam relacionados à luz das questões concretas que se pretende compreender” (Documento Base da Educação Profissional Técnica de Nível Médio Integrada ao Ensino Médio, 2007, p. 52).

O ensino e a aprendizagem de línguas estrangeiras, neste contexto, contribuiriam para a compreensão dos aspectos referentes à possibilidade de formular contra-discursos a toda e qualquer forma de dependência e desigualdade. O aluno, portanto, é visto como "um ser que tem desejos, crenças, atitudes e que constrói identidades e (inter)subjetividades; como um ator social moldado por seu gênero, etnia, classe social, e por processos sócio-históricos e sociopolíticos” (Assis-Peterson \& Silva, 2009, p. 98). Desta forma, o objetivo do ensino de línguas estrangeiras no ensino médio profissionalizante não seria o de apenas possibilitar a compreensão de textos técnicos na língua-alvo em aulas sobre estratégias de leitura, mas possibilitar a compreensão dos discursos produzidos na língua em questão sobre aspectos sócio-políticos referentes ao mundo do trabalho.

Diante disso, este texto pretende discutir o papel do ensino das línguas estrangeiras no contexto do ensino médio integrado. Inicialmente, abordamos os pressupostos que envolvem o ensino médio integrado ao ensino técnico relatando seu histórico, concepções e princípios. Em seguida, apresentamos uma discussão teórica sobre o ensino das línguas estrangeiras dentro de uma proposta crítica e, por último, apresentamos uma proposta interdisciplinar com a língua inglesa no ensino médio integrado ao curso técnico em Agropecuária. 


\section{ENSINO MÉDIO INTEGRADO: HISTÓRICO, CONCEPÇÕES E PRINCÍPIOS}

A compreensão da contribuição do ensino médio integrado para a educação brasileira passa, de acordo com Frigotto et al (op. cit.), pela histórica “dualidade entre cultura geral e cultura técnica” (p. 41). Segundo esses autores, o dualismo se enraíza historicamente em toda a sociedade brasileira por meio da escravidão e a conseqüente discriminação do trabalho manual.

Somente com o Decreto $\mathrm{n}^{0}$ 5.154, de 2004, que embasa a opção pela formação integral do trabalhador, e, posteriormente, com a Lei $\mathrm{n}^{\mathrm{0}} 11.741$, de 2008, é que se acrescenta à Lei de Diretrizes e Bases da Educação Nacional (LDB) uma das formas pelas quais a educação profissional técnica de nível médio será desenvolvida e articulada com o ensino médio.

A proposta da educação profissional técnica articulada ao ensino médio centra-se, conforme Frigotto et al (op. cit.), em "propiciar aos alunos o domínio dos fundamentos das técnicas diversificadas utilizadas na produção, e não o mero adestramento em técnicas produtivas” (Frigotto et al, 2005, p. 35). O objetivo profissionalizante se constituiria em "uma possibilidade a mais para os estudantes na construção de seus projetos de vida, socialmente determinados, possibilitados por uma formação ampla e integral” (Frigotto et al, 2005, p. 36). Para Ciavatta (2005), portanto, “a idéia de formação integrada supera o ser humano dividido historicamente pela divisão social do trabalho entre a ação de executar e a ação de pensar, dirigir ou planejar” (Ciavatta, 2005, p. 85). Desta forma, propõe-se também a formação de um sujeito crítico que perceba os fatos que ocorrem a sua volta e saiba, dentro deste contexto, se posicionar enquanto sujeito histórico, social e culturalmente constituído.

Em dezembro de 2007, é lançado o Documento Base da Educação Profissional Técnica de Nível Médio Integrada ao Ensino Médio a fim de apresentar “os pressupostos para a concretização dessa oferta, suas concepções e princípios e alguns fundamentos para a construção de um projeto político-pedagógico integrado” (Documento Base da Educação Profissional Técnica de Nível Médio Integrada ao Ensino Médio, 2007, p. 4). Este documento possui como concepções e princípios cinco eixos: a formação humana integral; trabalho, ciência, tecnologia e cultura como categorias indissociáveis da formação humana; o trabalho e a pesquisa como princípios educativos; e a relação parte-totalidade na proposta curricular. Estes eixos, contudo, encontram-se articulados. Abordaremos apenas o quinto eixo, pois o mesmo embasa os pressupostos teóricos deste texto.

A relação parte-totalidade na proposta curricular, no ensino médio integrado à 
educação profissional, pode estar presente a partir dos problemas que advêm da área profissional para a qual se preparam os estudantes. Mesmo que os processos de produção dessas áreas se constituam em partes da realidade mais completa, é possível estudá-los em múltiplas dimensões, de forma que, para compreendê-los, torna-se necessário recorrer a conhecimentos que explicam outros fenômenos que tenham o mesmo fundamento.

A partir de questões específicas, pode-se necessitar de conhecimentos gerais e, assim, apreendê-los para diversos fins além daqueles que motivaram sua apreensão. Para que isto seja possível, entretanto, é preciso estudar os problemas de uma área profissional em múltiplas dimensões, tais como econômica, social, política, cultural e técnica. Os conceitos “pontos-de-partida” para esse estudo revertem-se em conteúdos de ensino sistematizados nas diferentes áreas de conhecimento e suas disciplinas. Estamos, assim, relacionando parte e totalidade, conhecimentos gerais e específicos, contemporaneidade e historicidade. A interdisciplinaridade aparece, aqui, como necessidade e, portanto, como princípio organizador do currículo e como método de ensino-aprendizagem, pois os conceitos de diversas disciplinas seriam relacionados à luz das questões concretas que se pretendem compreender (cf.: Documento Base da Educação Profissional Técnica de Nível Médio Integrada ao Ensino Médio, 2007, p. 49-52).

Como é possível perceber, o eixo da relação parte-totalidade na proposta curricular converge para a substituição do modelo de formação geral em contraposição à formação específica para um modelo que possibilite a interligação entre ambas as formações. A interdisciplinaridade, portanto, torna-se crucial uma vez que supõe disciplinas que se interseccionam, mas não se sobrepõem, que se reorganizam, que buscam elementos em outras ciências. Ao mesmo tempo, a formação de um sujeito crítico surge como elemento inerente à interdisciplinaridade, pois esse constante diálogo entre as disciplinas contribui para a formação de um aluno que saiba relacionar e transferir saberes, marcas da formação para a pós-modernidade ${ }^{1}$.

\section{ENSINO E APRENDIZAGEM DE LÍNGUAS ESTRANGEIRAS: UMA VISÃO CRÍTICA}

O Documento Base da Educação Profissional Técnica de Nível Médio Integrada ao Ensino Médio (2007) prevê, implicitamente, a formação de um aluno que tenha uma visão

\footnotetext{
${ }^{1}$ O termo pós-moderno é utilizado neste texto na concepção de Habermas (1993).
} 
crítica do mundo que o cerca. O termo crítico nasce da pedagogia libertária e, posteriormente, da pedagogia crítica. De acordo com Silva (2004), o objetivo da pedagogia crítica é evidenciar o que está por trás das estruturas sociais que compactuam com a exploração dos mais pobres e oprimidos. Mediante o conhecimento crítico, acredita-se que seja possível provocar mudanças na atitude das pessoas, levando-as a lutar para que os mais pobres tenham seus direitos garantidos.

Conforme Silva (2004, p. 7), “conhecer se vincula a poder”. Nesse caso, o poder é concebido de maneira dialética: ao mesmo tempo em que as relações sociais da escola e da sociedade expressam dominação, também apresentam a possibilidade de resistência e de ação contra-hegemônica. Ser professor é ser político, é conhecer as ideologias que sustentam determinadas práticas, é conhecer as relações de poder que entrecruzam os sujeitos em diferentes contextos sociais, não ser neutro e transpor todo esse conhecimento para a sala de aula.

Desta forma, a língua trabalhada em sala de aula não pode mais ser concebida como neutra, pois ela é carregada de ideologia e de poder. A todo o momento, quando lançamos mão dela, em diversos contextos interacionais, nós a utilizamos para dar e receber informações, bens e serviços (Halliday, 1994 apud Papa, 2007). As escolhas lingüísticas, presentes nos textos ${ }^{2}$, nos fazem compreender como as pessoas se posicionam e posicionam os outros nas interações. O aluno tem que ter acesso a essa reflexão para que ele se forme enquanto “pessoa humana”, dona de seu discurso.

Para Oliveira (2006), o professor, como intelectual transformador, deve refletir sobre os princípios ideológicos que influenciam sua prática e conectar essa prática à teoria e às questões sociais mais amplas. Além de ter o conhecimento específico, o professor deve assumir seu papel social e, dessa forma, levar conhecimento histórico, cultural, político e social para seus alunos compreenderem as ideologias que movem as questões sociais que influenciam as pessoas no dia a dia fazendo com que elas representem, interpretem, compreendam e façam senso de algum aspecto da existência social.

Isso é possível com uma formação crítica. A pedagogia crítica é engajada nos problemas sociais, incorporando as experiências de vida dos oprimidos, suas histórias e valores. Para ela, a escola não é um espaço neutro em que apenas se transmitem conhecimentos imparciais, capazes de instruir e elevar o nível cultural dos educandos. Mais do que isso, é o local em que se mostra a principal função do sistema de ensino instaurado no

\footnotetext{
2 Texto é definido como uma instância da língua que desempenha um papel em um contexto de situação, seja nas trocas faladas ou escritas, é uma troca social de significado (Halliday \& Hasan, 1985, p.11).
} 
sistema capitalista - o de reproduzir os fundamentos de uma sociedade desigual e injusta (Silva, 2004). O principal objetivo da pedagogia crítica é, portanto, fortalecer as pessoas sem poder e transformar as desigualdades e as injustiças sociais existentes.

No Brasil, um grande colaborador dos estudos da pedagogia crítica é Paulo Freire ${ }^{3}$, cuja ação se dirige para a emancipação e transformação dos sujeitos. Para Freire (1997, p. 78), “a escola é o lugar da política”, ou seja, professores e alunos devem ter consciência crítica para que haja transformação da sociedade.

Ao trabalhar com a língua estrangeira moderna no Brasil, mais especificamente, a língua inglesa, temos um cenário em que os atores sociais são forçados a utilizarem a gramática de uma comunidade de fala, a qual eles não escolheram e, muitas vezes, sequer compreendem o porquê dessa obrigatoriedade no currículo.

Diante disso, alguns autores (Pennycook,1998; Rajagopalan, 2003/2005), ao discutirem sobre o ensino de língua inglesa no mundo, asseveram que as pessoas se dedicam à tarefa de aprender línguas estrangeiras porque isso sempre representou prestígio. A pessoa que fala uma língua estrangeira é admirada e considerada culta e distinta. Há uma escala de valores que apresenta a língua inglesa com fortes conotações ideológicas. Phillipson (1992, p. 47 apud Rajagopalan, 2003), por exemplo, apresenta o termo “linguicismo”, referindo-se "às ideologias, estruturas e práticas que são mobilizadas para legitimar, efetuar e reproduzir uma divisão desigual de poder e recursos - tanto material como não material - entre grupos demarcados com base lingüística”. Desse modo, a língua inglesa e sua cultura sempre são consideradas superiores por boa parte dos professores, quando eles não têm esta formação teórica.

Além disso, Fairclough (1997) caracteriza hegemonia como o domínio exercido pelo poder de um grupo sobre os demais, baseado mais no consenso que no uso da força. Durante as interações verbais, hegemonias são produzidas, reproduzidas, contestadas e transformadas. Dessa forma, os indivíduos inseridos em práticas sociais e discursivas são responsáveis pela manutenção e pela transformação das estruturas sociais. Resende \& Ramalho (2006) consideram ser a ideologia, por natureza, hegemônica, no sentido de que "ela necessariamente serve para estabelecer e sustentar relações de dominação e, por isso, serve para reproduzir a ordem social que fornece indivíduos e grupos dominantes” (Resende \& Ramalho, 2006, p. 49). Portanto, o professor de língua estrangeira na pós-modernidade deve estar mais preocupado na formação do aluno que saiba utilizar a língua estrangeira, não apenas para

\footnotetext{
${ }^{3}$ Ver Cox e Assis-Peterson (1999) para breve histórico do nascimento da pedagogia crítica no Brasil.
} 
produzir textos em diversos contextos interacionais, mas também perceber as relações de poder que fazem parte de qualquer língua.

\section{UMA PROPOSTA DE TRABALHO COM A LÍNGUA INGLESA NO ENSINO MÉDIO INTEGRADO AO CURSO TÉCNICO EM AGROPECUÁRIA ${ }^{4}$}

Esta proposta de trabalho com a língua inglesa pressupõe tratar os diferentes campos do conhecimento da agropecuária de forma integrada com outras áreas do conhecimento. Ao mesmo tempo, nossa concepção é de que formar o aluno de um curso técnico em agropecuária integrado ao ensino médio significa também formar gestores do campo responsáveis sócioambientalmente.

Desta forma, a prática de sala de aula deve estar pautada em teorias que possibilitem a reflexão do papel do aluno enquanto um agente transformador por meio do uso de textos ${ }^{5}$ que realmente mexam com as crenças cristalizadas e promovam novas reflexões para a vida e para o trabalho, assim como reativem o conhecimento prévio e o diálogo com outras áreas de conhecimento, que se constitui uma necessidade diante da proposta do ensino médio integrado.

O trecho abaixo do texto The Cow Turns Green ${ }^{6}$, publicado na Revista Newsweek de 07 de setembro de 2009, pode representar um bom exemplo de trabalho interdisciplinar na medida em que possibilita integrar áreas da agropecuária na discussão sobre os impactos ambientais da produção de alimentos e a busca de soluções pela ciência em tentar minimizar estes impactos. A parte utilizada na proposta apresentada neste artigo está transcrita abaixo ${ }^{7}$.

\section{THE COW TURNS GREEN}

Vilified as an environmental disaster, the meat industry, abetted by science, is now trying to change its way.

\section{By Mac Margolis}

Few creatures would seem as beneficent as the cow. Properly grazed and groomed, it gives us burgers and brie, boot leather and fertilizer. Lately, however, radical green groups and celebrity vegans like Paul McCartney have made cows out to be weapons of mass destruction: not only has their meat caused an epidemic of hypertension and heart disease, but they also trample rainforests, trash the soil, and foul the air with greenhouse gases.

\footnotetext{
${ }^{4}$ Proposta baseada em nossas experiências no IFMT.

${ }^{5}$ Conforme definição apresentada anteriormente.

${ }^{6}$ Ver Anexos.
} 
Scientists say that every year the average Holstein produces up to 180 kilos of methane, which traps 25 times more heat than does carbon dioxide. All told, bringing meat from the pasture to the griddle produces 18 percent of global greenhouse-gas emissions, according to the United Nations. Last year, Rajendra Pachauri, the chair of the U.N.'s Intergovernmental Panel on Climate Change, called upon everyone to give up eating meat at least one day a week, giving birth to the global meatless Monday. "If anyone wants to save the planet, all they have to do is just stop eating meat”, McCartney famously said.

Quadro 1 - Transcrição de parte do texto The Cow Turns Green, publicado na Revista Newsweek de 07 de setembro de 2009.

O papel da língua inglesa, neste propósito, torna-se crucial, pois a partir do título do texto já é possível iniciar uma proposta de trabalho sobre a discussão do termo green na contemporaneidade. Os vários discursos que permeiam ser green, ancorados por organizações não-governamentais, como Greenpeace e WWF, e as Nações Unidas, na luta pela preservação do meio ambiente e a redução dos impactos provocados pelo homem, aparecem também na agropecuária, que é tida como uma das grandes vilãs devido à utilização de agrotóxicos e à devastação de grandes áreas para o plantio de pastagens ou cultivo de grãos, por exemplo.

Observa-se, entretanto, que, de acordo com o texto, a pesquisa em bovinocultura e a indústria de produção de carnes e derivados também começam a se preocupar em buscar soluções para as questões ambientais, isto é, para a redução dos impactos que as mesmas produzem ao meio ambiente, como, de acordo com o texto, a diminuição da emissão de gás metano que contribui para o aquecimento global. É possível levantar, portanto, inúmeras críticas à criação de bovinos ao longo do texto. Entretanto, a principal estratégia que permeia todos os esforços apresentados pela bovinocultura, no texto, continua sendo o discurso da conservação e da conscientização ambiental como formas de promoção do consumo. Um green beef solucionaria todos os problemas que a indústria da carne bovina produz.

Como uma forma de fomentar a discussão, é possível propor exercícios de estratégias de leitura (como scanning), que envolvem encontrar informações precisas no texto. Apresentamos uma sugestão abaixo.

Preencha o quadro com a descrição de cada um dos grupos em relação à indústria da bovinocultura.

\begin{tabular}{|l|l|}
\hline $\begin{array}{l}\text { a) Grupos ambientalistas radicais e } \\
\text { vegetarianos }\end{array}$ & \\
\hline b) Cientistas/Nações Unidas (ONU) & \\
\hline
\end{tabular}

Quadro 2 - Exercício de scanning.

Sobre este mesmo exercício, é possível ainda questionar a localização das perspectivas 
de cada um dos grupos acima e suas implicações. Como nos lembra Jordão (2007),

a escola pode ensinar as pessoas a reconhecerem que aquele que fala, fala sempre de algum lugar, para outros que se posicionam em lugares também específicos. E que o falar e o agir, portanto, sendo localizados, vem de determinadas perspectivas ideológicas, culturais, coletivamente construídas, e tem sempre implicações nas construções identitárias daqueles que com eles interagem. (Jordão, 2007, p. 24)

Portanto, é de certa forma esperado que cada um dos grupos citados no exercício assuma determinada perspectiva ideológica haja vista o "local” de onde "falam”. O papel da escola seria, de acordo com a citação acima, ensinar as pessoas a reconhecerem as perspectivas e suas implicações na construção de processos socioculturais e ideológicos.

Assim, é importante ressaltar que uma prática interdisciplinar, mediada por um texto em língua inglesa, em um curso de ensino médio integrado, promove o diálogo entre várias áreas de conhecimento e promove reflexões sobre o papel do aluno que está sendo formado. O conhecimento da língua em si é imprescindível, uma vez que este também é um objetivo que as aulas de línguas devem desenvolver. Uma possibilidade aqui seria a construção de um dicionário de termos técnicos e/ou específicos da agropecuária ao longo das aulas a partir dos textos estudados.

Entretanto, como é possível perceber, o ensino e a aprendizagem de línguas estrangeiras não se limitam a aspectos lingüísticos apenas, pautados na metalinguagem. Como mencionamos anteriormente, as línguas estrangeiras podem possibilitar a formação de um aluno que tenha uma visão crítica do mundo que o cerca, saiba se situar sóciopoliticamente para compreender este mundo e proceda para galgar outras realidades possíveis.

\section{CONSIDERAÇÕES FINAIS}

Haja vista as inúmeras possibilidades de interdisciplinaridade, o papel do ensino e da aprendizagem de línguas estrangeiras dentro da proposta do Ensino Médio Integrado é crucial para uma formação mais crítica, pois, conforme apresentamos neste texto, propõe a possibilidade de o aluno estudar os problemas da área profissional em múltiplas dimensões, tais como econômica, social, política, cultural e técnica. Desta forma, a formação do profissional não se limitaria a aspectos técnicos, voltados apenas para a execução da profissão, mas torna possível a formação integral de um sujeito que também está inserido em uma sociedade e suas teias de poder que tentam determinar e estabelecer os discursos 
assumidos como verdadeiros e, portanto, válidos.

De acordo com Fairclough,

\begin{abstract}
mesmo quando nossa prática pode ser interpretada como de resistência, contribuindo para a mudança ideológica, não estamos necessariamente conscientes dos detalhes de sua significação ideológica. Essa é uma razão para se defender uma modalidade de educação lingüística que enfatize a consciência crítica dos processos ideológicos no discurso, para que as pessoas possam tornar-se mais conscientes de sua própria prática e mais críticas dos discursos investidos ideologicamente a que são submetidos. (Fairclough, 2001, p. 120)
\end{abstract}

Portanto, possibilitar ao aluno conhecer as concepções e as práticas discursivas veiculadas por línguas estrangeiras que, por sua vez, expõem as visões de mundo que os povos que as utilizam possuem, muito pode contribuir para a formação que se espera de um curso técnico integrado ao ensino médio. A superação da dualidade entre cultura geral e cultura técnica depende do envolvimento que empenhamos na busca pela formação de um cidadão ciente dos processos culturais, econômicos, políticos e sociais que permeiam a sua prática social.

\title{
REFERÊNCIAS
}

Assis-Peteron, A. A. de \& Cox, M. I. P. (2007). Inglês em tempos de globalização: para além de bem e mal. Calidoscópio, 5 (1), 5-14.

Assis-Peterson, A. A. de \& Silva, E. M. N. da (2009). Alunos à margem das aulas de inglês: por uma prática inclusiva. In Lima, D. C. de (org.). Ensino e aprendizagem de língua inglesa. São Paulo: Parábola.

Brasil, Secretaria de Educação Profissional e Tecnológica. (2007). Documento base da educação profissional técnica integrada ao ensino médio.

Ciavatta, M. (2005). A formação integrada: a escola e o trabalho como lugares de memória e de identidade. In Frigotto, G. et al (org.). Ensino médio integrado: concepções e contradições. São Paulo: Cortez.

Cox, M. I. P. \& Assis-Peterson, A. A. de. (1999). ELT: images of Brazilian Teachers of English. Tesol Quartely, 33 (3), 433-452.

Fairclough, N. (1997). Discurso, mudança e hegemonia. In Pedro, E.R. (org.). Análise crítica do discurso: uma perspectiva sociopolitical e functional. Lisboa: Caminho, 77-104. 
Freire, P. (1997) Pedagogia da esperança: um reencontro com a pedagogia do oprimido. Rio de Janeiro: Paz e Terra.

Frigotto, G.; Ciavatta, M.; \& Ramos, M. (2005). A gênese do Decreto n. 5.154/2004: um debate no contexto controverso da democracia restrita. In Frigotto, G. et al (org.). Ensino médio integrado: concepções e contradições. São Paulo: Cortez.

Habermas, J. (1993). Modernity - an incomplete project. In Docherty, T. (org.) Postmodernism: a reader. London: Harvester Wheathsheaf, 98 - 109.

Halliday, M. A. K. \& Hasan R. (1985). Language, context and text: aspects of language in a social-semiotic perspective. Oxford: Oxford University Press.

Jordão, C. M. (2007). As lentes do discurso: letramento e criticidade no mundo digital. Trabalhos de Lingüística Aplicada, 46 (1), 19-29.

Margolis, M. (2009). The cow turns green. Revista Newsweek, CLIV (10).

Oliveira, A. L. A. M. (2006). Hermes e bonecas russas: um estudo colaborativo para compreender a relação teoria-prática na formação docente. Tese de doutorado inédita, UFMG.

Papa, S. M. de B. I. (2007). Prática pedagógica emancipatória: o professor reflexivo em processo de mudança - um exercício em análise crítica do discurso. São Carlos: Pedro e João Editores.

Pennycook, A. (1998). A lingüística aplicada dos anos 90: em defesa de uma abordagem crítica. In Signorini, I. \& Cavalcanti, M. C. (org). Lingüística aplicada e transdisciplinaridade: questões e perspectivas. Campinas: Mercado de Letras, 23-49.

Rajagopalan, K. (2005). O grande desafio: aprender a dominar a língua inglesa sem ser dominado por ela. In Gimenez, T.; Jordão, C. M. \& Andreotti, V. (org). Perspectivas educacionais e o ensino de inglês na escola pública. Pelotas: EDUCAT, 37-48.

São Paulo: Parábola.

(2003). Por uma lingüística crítica: linguagem, identidade e a questão ética.

Resende, V. M. \& Ramalho, V. (2006). Análise do discurso crítica. São Paulo: Contexto.

Silva, A. O. (2004). Pedagogia libertária e pedagogia crítica. Revista Espaço Acadêmico, 42 (1). 


\section{ANEXOS}

\section{ENVIRONMENT FARMING \\ THECOWTURNSGREEN}

Vilified as an environmental disaster, the meat industry,

abetted by science, is now trying to change its ways.

BY MAC MARGOLIS

FEW CREATURES WOULD SEEM AS BENEFICENT AS THE COW. PROPERLY grazed and groomed, it gives us burgers and brie, boot leather and fertilizer. Lately, however, radical green groups and celebrity vegans like Paul McCartney have made cows out to be weapons of mass destruction: not only has their

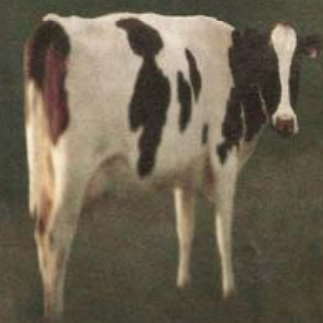
meat caused an epidemic of hypertension and heart disease, but they also trample rainforests, trash the soil, and foul the air with greenhouse gases. Scientists say that every year the average Holstein produces up to 180 kilos of methane, which traps 25 times more heat than does carbon dioxide. All told, bringing meat from the pasture to the griddle produces 18 percent of global greenhouse-gas emissions, according to the United Nations. Last year, Rajendra Pachauri, the chair of the U.N.'s Intergovernmental Panel on Climate Change, called upon everyone to give up eating meat at least one day a week, giving birth to the global meatless Monday. "If anyone wants to save the planet, all they have to do is just stop eating meat," McCartney famously said.

Fonte: Revista Newsweek, 07 de setembro de 2009 


\section{OS AUTORES}

\section{Fernando Zolin-Vesz}

Instituto Federal de Educação, Ciência e Tecnologia de Mato Grosso (IFMT)

Técnico em Assuntos Educacionais do IFMT, graduado em Letras - Português/Inglês pela Universidade Federal de Santa Maria (UFSM) e mestrando em Estudos de Linguagem pela Universidade Federal de Mato Grosso (UFMT).

E-mail: fernando.vesz@svc.ifmt.edu.br

\section{Veralúcia Guimarães de Souza}

Instituto Federal de Educação, Ciência e Tecnologia de Mato Grosso (IFMT)

Professora do IFMT - Campus Cuiabá Bela Vista, graduada em Letras pela Universidade Federal de Mato Grosso (UFMT), mestre em Estudos de Linguagem pela Universidade Federal de Mato Grosso (UFMT) e doutoranda em Linguística pela Universidade de Brasília (UnB).

E-mail: veraluciags@terra.com.br 